\title{
Undescended testis and hormone levels in early pregnancy
}

\author{
M H BURTON, ${ }^{1}$ T W DAVIES, ${ }^{2}$ AND P R RAGGATT ${ }^{3}$ \\ From the Cambridge Health Authority: ${ }^{\prime}$ the Department of Community Medicine, ${ }^{2}$ University of Cambridge; and \\ the Department of Biochemistry, ${ }^{3}$ Addenbrooke's Hospital, Cambridge.
}

SUMMARY A case-control study was carried out on mothers of boys with undescended testis to investigate the hypotheses that raised maternal levels of oestrogen or reduced levels of human chorionic gonadotrophin in early pregnancy might be factors in the environment of the fetus associated with this condition. No significant difference in the levels of either of these hormones was found, though, if anything, levels of oestrogen may have been lower in cases than in controls, and not higher as previously postulated.

This study was undertaken to investigate a possible relation between undescended testis and maternal levels of oestrogen and human chorionic gonadotrophin (HCG) in early pregnancy.

The importance of information on the epidemiology of this condition arises not only from its consequences of infertility or subfertility, but also from its association with carcinoma of the testis. The incidence of this malignancy is rising in the UK and other European countries, ${ }^{1}$ and undescended testis is the main known risk factor. ${ }^{2}$ Interestingly, however, an increased risk of malignancy is present not only for the undescended testis but also for a normally descended organ on the other side. ${ }^{3}$ This suggests that the early development of both testes is in some way abnormal, thus predisposing them to both maldescent and cancer.

The causes of this initial abnormality are unknown, but some environmental factor, which is altered in the first trimester of pregnancy when the testes are developing, has been postulated.

Two contrasting hypotheses have been put forward. The first involves exposure to high levels of oestrogen during this period. There are several reasons for supporting this theory. Treatment of mothers with diethylstilboestrol is associated with both testicular tumours and undescended testis. ${ }^{4}$ Henderson et al found that nausea in early pregnancy, which is thought to result from high oestrogen levels, was associated with both conditions. ${ }^{3}$ Hypertension, again previously related to high oestrogen, has been associated with undescended testis. ${ }^{5}$ Finally, maternal obesity has also been linked with undescended testis and carcinoma of the testis. ${ }^{6}$ As has been suggested with endometrial cancer, this may be via reduced levels of sex hormone binding globulin causing raised free oestrogen.

The second contrasting hypothesis is that of reduced placental function. This has been put forward on the basis of a case-control study of mothers of boys with undescended testis. ${ }^{7}$ In this study there was some evidence of reduced fertility, more miscarriages of sibling pregnancies, fewer terminations of pregnancy, and more threatened abortions in the index pregnancy. This led to the suggestion that the mother had a tendency to reject the placenta. One hormone which is produced by the placenta and is involved with the maintenance of pregnancy is HCG. Reduced levels may be associated with an increasing threat of miscarriage. While only about $2 \%$ of HCG finds its way to the fetus, the levels of HCG in maternal plasma are very high in the first trimester, and this hormone is also thought to be responsible for controlling early development of the testis. ${ }^{8}$

\section{Method}

Cases of undescended testis were identified from patients referred to consultant surgeons at Addenbrooke's Hospital, Cambridge and the Ipswich Hospital, Ipswich.

The source of maternal serum for measuring hormone levels was the Public Health Laboratory Service where sera taken for antenatal estimation of rubella antibodies were stored. Control samples were identified as the next antenatal rubella specimen to be assayed on the same day.

Total plasma oestradiol was measured by a ${ }^{125} \mathrm{I}$ labelled non-extraction radioimmunoassay (Steranti Research Ltd). The antibody is highly specific for 17B 
oestradiol; cross reactivity with oestrone and oestriol is approximately $2 \%$, and with other steroid glucuronides is less than $0 \cdot 1 \%$.

Plasma HCG was measured by radioimmunoassay using the Amerlex-M kit (Amersham International, Amersham, UK). Cross reactivity with follicle stimulating hormone (FSH), luteinising hormone (LH), and thyroid stimulating hormone (TSH) is very low and, as these samples had to be diluted 1000-fold before assay because of the high levels of HCG in pregnancy, it is thought that there was virtually no contribution to the result by FSH, LH, or TSH, ie, the contribution must be $<1.0 \mathrm{u} / \mathrm{l}$.

\section{Results}

Ninety-seven cases of undescended testis were ascertained from the surgical department, and in 30 of these serum for measurement of oestradiol together with a reliable estimate of duration of pregnancy was available. Oestradiol was measured for 30 controls.

The relation between total serum oestradiol levels and the number of days' gestation was plotted for cases and controls (figure).
Nineteen cases and 22 controls had blood taken during the first 100 days of pregnancy, the period within which the testes become differentiated. During this time there was very little rise in oestradiol levels with gestational age, and for controls there was no significant change. The mean oestradiol levels were higher in controls $(8.9 \mathrm{pmol} / 1, \mathrm{SD} \pm 4.79)$ than in cases $(6.2 \mathrm{pmol} / 1, \mathrm{SD} \pm 6.74)$ despite the slightly shorter mean length of gestation in controls ( 75 days) than in cases (77 days). The difference in oestradiol level was not statistically significant (difference $=2 \cdot 7$ $\mathrm{pmol} / 1,95 \%$ confidence interval -0.91 to 6.31 ).

When all cases and controls are included, some samples being taken at lengths of gestation greater than 100 days, a rise of oestradiol levels with gestational age becomes apparent. However, the results are similar, controls showing a higher mean value of oestradiol levels $(14.1 \mathrm{pmol} / 1, \mathrm{SD} \pm 7.06)$ than cases $(10.0 \mathrm{pmol} / 1, \mathrm{SD} \pm 12.49)$ in spite of the shorter mean value of gestation in controls $(90 \vee 94$ days). Again, this difference in oestradiol levels was not statistically significant (difference $=4 \cdot 1 \mathrm{pmol} / 1$, $95 \%$ confidence interval $=1 \cdot 14$ to $9 \cdot 34$ ).

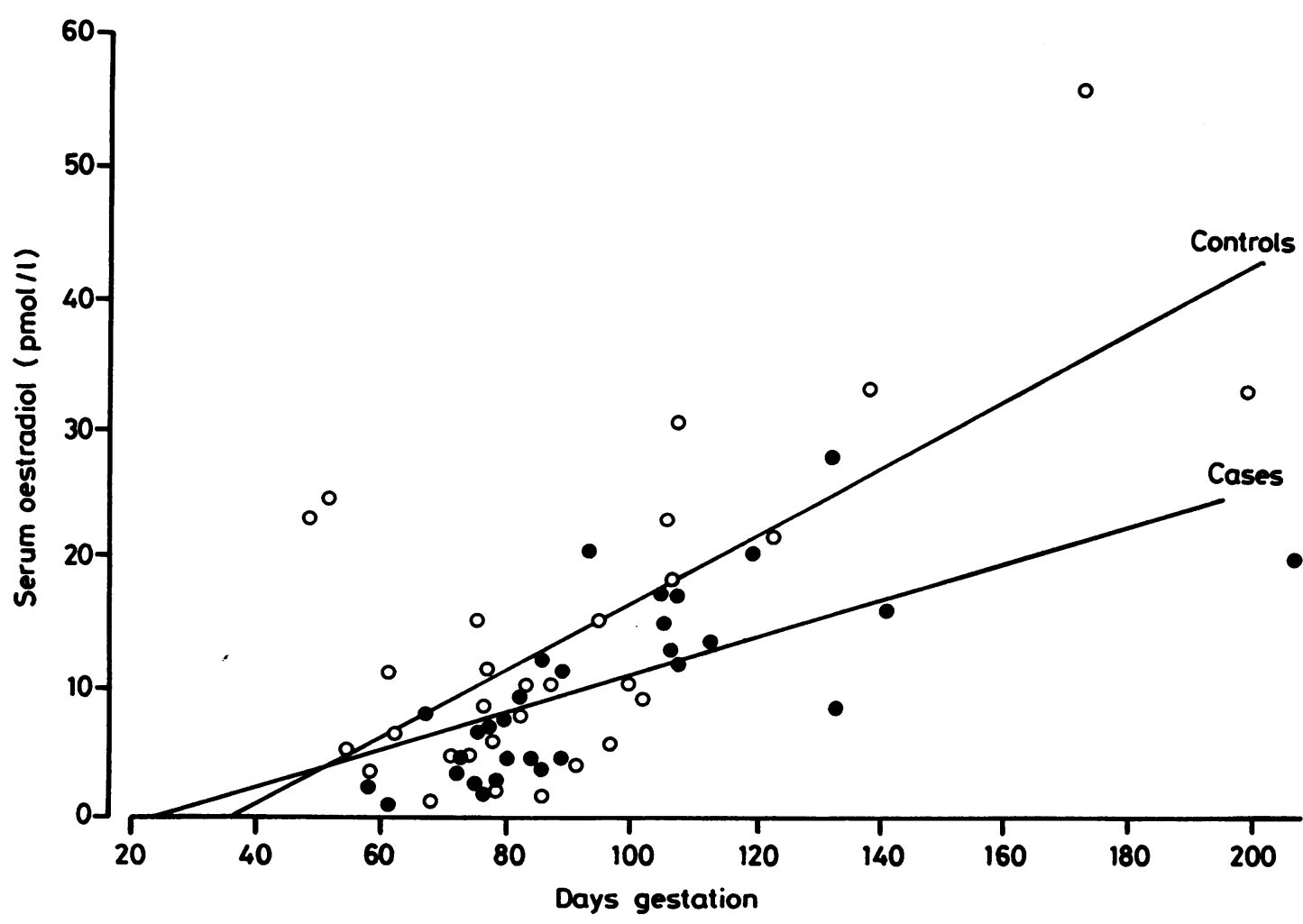

Serum oestradiol concentration in relation to gestational age for 30 cases (O) and 30 controls (O). 
Levels of serum HCG and a reliable estimate of gestational age were available for 25 cases and 32 controls, a slightly different set of samples from those used in the oestrogen study. Published normal values of HCG show that levels rise very rapidly in early pregnancy, reaching a peak at around 80 days and returning to lower levels at 140 days. Variations between HCG levels from different subjects at any point during pregnancy are, however, more than 10-fold. Most of our results were obtained within the peak period and fell within normal expected ranges, but with the small number of points available it was impossible to detect any differences between cases and controls, whether all samples were included (mean value for cases $=35.8 \mathrm{ku} /$ litre, controls $=35.5 \mathrm{ku} /$ litre) or only those measured within the first 100 days (mean value for 18 cases $=39.0 \mathrm{ku} / \mathrm{litre}$, for controls $=41 \cdot 2 \mathrm{ku} /$ litre).

\section{Discussion}

Inevitable limitations were imposed on this study by the small number of cases for whom maternal serum was available, even after an intensive search in the East Anglian Region. The source of maternal serum was those few districts which store the serum taken for antenatal estimation of rubella antibodies. As undescended testis may not be recognised until the patient is over 2 years of age, serum must be kept for up to three years, and in East Anglia only Cambridge and Ipswich fulfilled this criterion. Even in those districts serum was not available for all mothers, the test being unneccessary, for example, if a mother is already known to be immune. Some bias may therefore have been introduced towards mothers in their first pregnancy, but this would occur in both cases and controls.

To overcome this problem of the availability of serum would require a cohort study involving the collection of blood from all pregnant mothers and the storage of all specimens for at least two to three years until cases were identified.

The problems of the study were exacerbated by the wide normal ranges of the hormones measured and the large fluctuations during pregnancy.

However, regarding oestrogen levels, if any differences exist between mothers of boys with undescended testis and normal controls, these differences are not large, and, if anything, oestrogen may be lower in cases than in controls and not the other way round as postulated. There is thus no support for the hypothesis that maternal oestrogens are a common causative factor in undescended testis and testicular cancer. The results regarding HCG levels are also disappointingly inconclusive, although they suggest that large and important differences are unlikely.

We thank Mr $\mathbf{R}$ Whitaker and his surgical colleagues at Cambridge and Ipswich Hospitals for allowing us access to their patients, Dr Taylor and Mr Smith of the Public Health Laboratory who permitted us to examine the sera, and Dr N Mamujee of the Public Health Laboratory Service for help in obtaining the sera and relevant data in Ipswich. Thanks are also due to Sarah Roberts for statistical help. This work was supported by grants from the Peel Medical Research Trust and the Beebe Fund of the University of Cambridge.

\section{References}

${ }^{1}$ Davies JM. Testicular cancer in England and Wales: some epidemiological aspects. Lancet 1981; ii: 928-32.

${ }^{2}$ Gilbert JB, Hamilton JB. Studies in malignant tumours. III. Incidence and nature of tumours in ectopic testes. Surg Gynecol Obstet 1940; 71: 731-43.

${ }^{3}$ Henderson BE, Benton B, Jing J, Yu MC, Pike MC. Risk factors for cancer of the testis in young men. Int $J$ Cancer 1979; 23: 598-602.

${ }^{4}$ Cosgrove MD, Benton B, Henderson BE. Male genitourinary abnormalities and maternal diethylstilboestrol. J Urol 1977; 117: 220-2.

${ }^{5}$ Chung CS, Myrianthopoulous NC. Factors affecting risks of congenital malformations. 1. Epidemiologic analysis. In: Bergsma D, ed. Birth defects: Original article series, Vol XI, No 10. White Plains: The National Foundation, 1975.

${ }^{6}$ Depue RH, Pike MC, Henderson BE. Estrogen exposure during gestation and risk of testicular cancer. $J$ Natl Cancer Inst 1983; 71: 1151-5.

${ }^{7}$ Davies TW, Williams DRR, Whitaker RH. Risk factors for undescended testis. Int J Epidemiol in press.

${ }^{8}$ Kaplan SL, Crumback MM. Pituitary and placental gonadotrophins and sex steroids in the human and subhuman primate fetus. Clinics in Endocrinology and Metabolism, Vol 7, No 3, November 1978. 